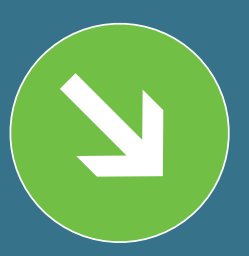

Ключевые слова:

вибромониторинг,

вибродиагностика,

аутсорсинг, проак-

тивное техобслу-

живание, ТОиР

\title{
АУТСОРСИНГ «НАДЕЖНОСТИ ОБОРУДОВАНИЯ»
}

\section{Александр НАЗАРЕНКО, Алексей БАННИКОВ}

Предложена концепция проактивного техобслуживания от компании SKF, которая объединяет мониторинг состояния оборудования с обнаружением причин преждевременного выхода оборудования из строя, разработкой мероприятий по устранению этих причин и документальным контролем эффективности внедрения.

\section{ВВЕДЕНИЕ}

На рынке существует множество компаний, занимающихся разработкой и производством электронных приборов и/или программного обеспечения для контроля состояния оборудования по параметрам вибрации. Маркетинговые кампании в данном сегменте зачастую основываются на том, что с помощью вибромониторинга и вибродиагностики заказчик сможет перейти на техобслуживание по фактическому состоянию и, таким образом, снизить затраты на техобслуживание и ремонт. Также, особенно в последние годы, на рынке появились компании предлагающие услуги по вибродиагностике и виброналадке (балансировка, центровка и т. д.) с теми же утверждениями о том, что их услуги позволят избежать аварий и непредвиденного выхода оборудования из строя.

Оба вида бизнеса безусловно могут принести не только коммерческую выгоду компаниям, которые оказывают подобные услуги, но и пользу потреби- телям этих приборов и/или услуг. Однако успех их внедрения или применения в конечном счете все равно зависит от квалификации персонала заказчика и того, насколько эффективно его специалисты способны использовать данные технологии и результаты предоставляемых услуг для решения основной задачи предприятия - увеличения времени наработки на отказ (Mean Time Before Failure - MTBF) или наработки до ремонта (Mean Time To Repair - MTTR).

В большинстве случаев заказчик не обладает такими ресурсами и квалификацией, которые смогут конвертировать затраченные средства в реальное повышение эффективности технического обслуживания.

\section{КОНЦЕПЦИЯ ПРОАКТИВНОГО ТЕХОБСЛУЖИВАНИЯ SKF}

SKF использует мониторинг состояния и дополняет его элементами, необходимыми для образования

\section{Цикл проактивного Т0 - непрерывный процесс улучшений}

Мониторинг состояния (вибромониторинг, обходы мобильного ТОиР, сопровождение ремонтов)
План мероприятий по устранению причин неисправностей (обучение персонала, модернизация, корректировка Т0)
Контроль по ключевым показателям (KPI)

Внедрение мероприятий

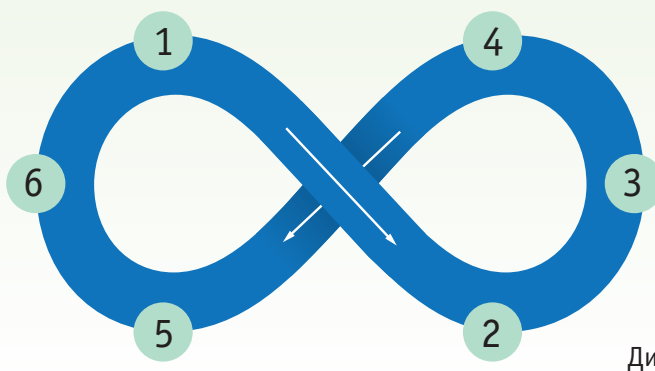

Диагностика неисправностей, документирование отклонений, анализ практик ТО
Анализ причин возникновения неисправностей (RCFA)

Puc. 1. Цикл проактивного Т0 


\section{Концепция проактивного Т0 нацелена на переход из точки 1 в точку 2}

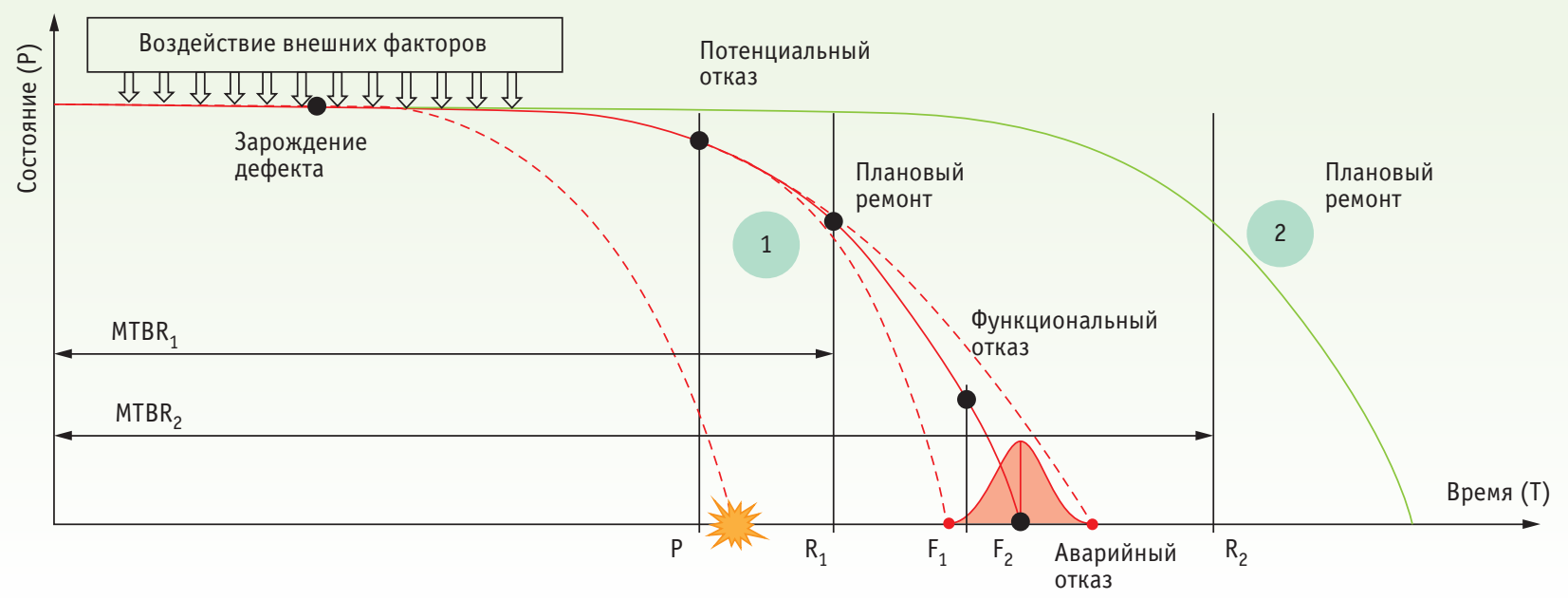

\section{Puc. 2. Концепция проактивного TO SKF}

цикла устойчивого повышения эффективности ТО (рис. 1,2) - обнаружение причин преждевременного выхода оборудования из строя, разработка мероприятий по устранению этих причин, их внедрение и документальный контроль эффективности внедрения.

Здесь необходимо также отметить принципиальную разницу между мониторингом и диагностикой. Важнейшими аспектами мониторинга являются долгосрочность, неукоснительное соблюдение графика проведения измерений, обязательная регистрация и хранение результатов в виде трендов параметров. При наличии аппаратных и программных средств задача мониторинга вполне по силам самому предприятию-владельцу оборудования. Эта задача также достаточно просто может быть автоматизирована. В свою очередь, задача диагностики неисправностей безусловно требует привлечения высококвалифицированного и высокооплачиваемого специалиста, оснащенного дорогостоящим точным аналитическим оборудованием, или применения современных техник диагностики с использованием

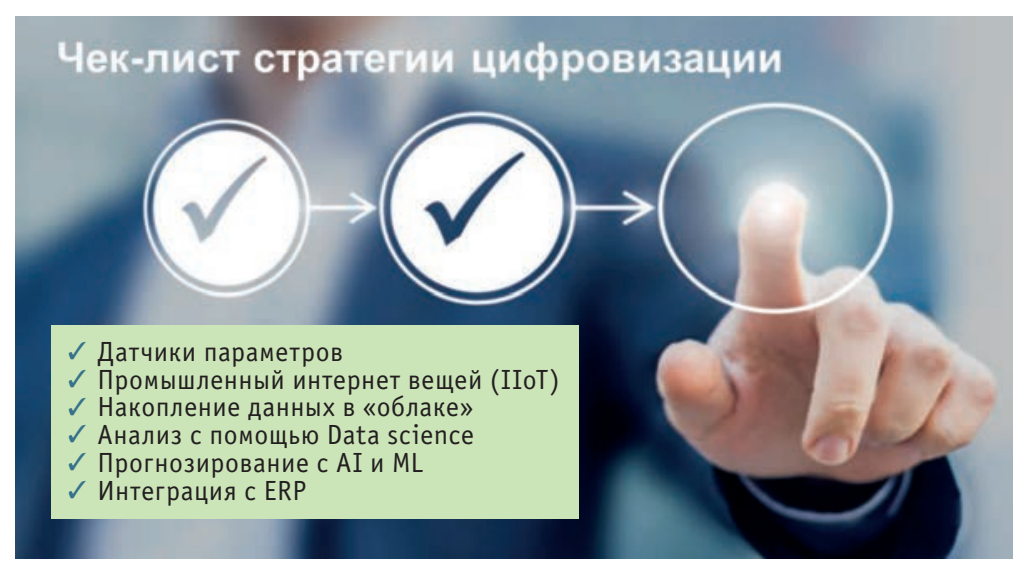

Puc. 3. Модель ИНС для мониторинга станка искусственного интеллекта (рис. 3, см. ст. «Передовые технологии мониторинга состояния оборудования» в журнале СТАНКОИНСТРУМЕНТ, 2019, № 2 (015)).

Переход к такой модели диагностики подразумевает целенаправленное и последовательное внедрение на предприятии стратегии цифровизации, что, конечно, является вопросом достаточно отдаленного будущего, которым, тем не менее, нужно заниматься уже сейчас (рис. 4).

\section{ЧТО МОЖНО СДЕЛАТЬ УЖЕ СЕЙЧАС?}

Даже если задачи мониторинга и диагностики реализованы в такой степени, как описано выше (что, как правило, встречается достаточно редко), без внедрения системы эффективных организационных и инженерных решений, направленных на повышение надежности оборудования, задача увеличения межремонтного интервала останется нерешенной. Проще говоря, оборудование не перестанет неожиданно и неконтролируемо выходить из строя, если вы ограничитесь только применением мониторинга его состояния.

Под организационными мерами здесь мы понимаем, например, эффективное использование программных пакетов ЕАМ или CMMS для управления техобслуживанием (наибольшее распространение в России имеют SAP PM, 1C:ТОИР, Oracle EAM). Также на предприятии должна быть налажена система обучения и повышения квалификации персонала. В свою очередь, для последовательного внедрения данных решений и устойчивого развития предприятия, необходимы два фактора, определяющие успех, - управленческая воля руководства 


\section{Модель интеллектуальных нейронных сетей для мониторинга станка}

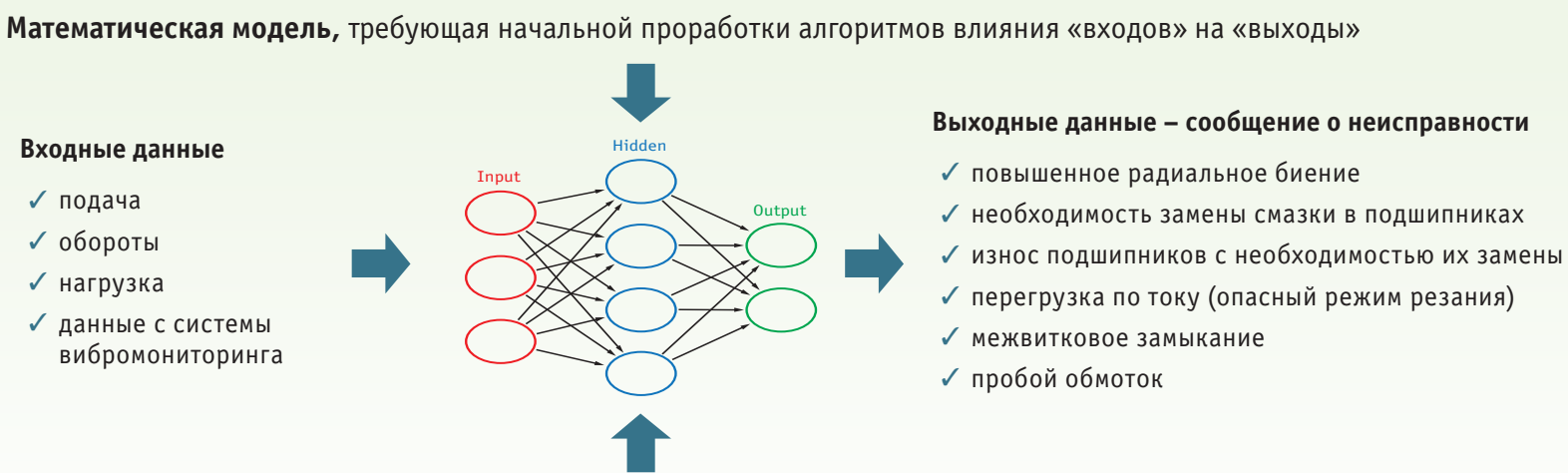

Модель ИНС, используется в вычислениях на серверах ЦОД с применением методов «машинного обучения» для повышения достоверности результатов анализа

\section{Puc. 4. Чек-лист стратегии цифровизации}

к переменам и производственная дисциплина. Все это является вполне достижимым и полностью находится в руках самих предприятий.

B компании SKF хорошо понимают и отдают себе отчет в том, что показанная выше картина организации и выполнения техобслуживания является скорее идеалистической моделью, к которой нужно стремиться, чем практическим руководством для достижения совершенства. На предприятиях заказчиков видны искренние и настойчивые попытки внедрения отдельных элементов данной «совершенной» модели. Однако доведение даже этих отдельных элементов до результата зачастую является затруднительным ввиду недостатка собственных ресурсов - как квалификации, так и времени у сотрудников предприятия.

Неудивительно, что в данной ситуации предприятия обращаются к сторонним поставщикам услуг в области техобслуживания и ремонта. Логика «аутсорсинга» проста и понятна - предприятие должно оставить у себя только те функции, которые направлены на обеспечение производства продукции в необходимом количестве и с заданным качеством в соответствии с рыночным спросом. Успешная деятельность предприятия (т.е. прибыль акционеров) зависит от совершенства технологий и эффективности их применения. Передача остальных функций сторонним организациям зачастую может оказаться более экономически эффективным решением.

К таким функциям на многих ведущих предприятиях относятся техническое обслуживание и ремонт (ТОиР). Предприятие оставляет за собой функции контроля выполнения работ по ТОиР, а сами работы передаются привлеченным подрядным организациям.

В этой области работают как консалтинговые, так и крупные промышленные компании, такие как SKF, которые имеют собственные инженерные кадры и производственные мощности.

\section{НОВЫЕ БИЗНЕС МОДЕЛИ}

Компания SKF уже более 25 лет предоставляет услуги по мониторингу и диагностике состояния узлов вращения в оборудовании. Как было описано выше, выполнение отдельных элементов практик проактивного ТО не приводит к выполнению комплексных целей заказчика, таких как сокращение совокупной стоимости владения (ТСО) или повышение эксплуатационной готовности оборудования. В связи с этим SKF разработала специальные программы комплексного технического обслуживания (Rotating Equipment Perfomance, Rotation for Life), направленные на повышение производительности узлов вращения. Концепция заключается в долгосрочном сотрудничестве для повышения эксплуатационной готовности оборудования клиента и снижения его совокупной стоимости владения. Фактически, компания SKF предлагает на аутсорсинг не просто набор технологий и продуктов, а комплексную функцию обеспечения «надежности оборудования».

Техническая реализация таких программ основывается на компетенциях SKF в области производства, применения, а также многолетней истории мониторинга состояния и обслуживания своей продукции в различных отраслях, включая станкостроительную. В рамках данной комплексной программы заказчик получает не отдельные услуги и продукты, а фактический аутсорсинг функции «Надежность оборудования». При заключении долгосрочного договора на комплексное техническое обслуживание SKF принимает на себя гарантийные обязательства по времени наработки узлов вращения на отказ (MTTF), и в случае недостижения целевых показателей выполняет гарантийное обслуживание узлов.

\section{0 «СКФ»}

тел.: +7 (495) 510-18-20, e-mail: SKF.Moscow@skf.com 


\section{ИЗДАТЕЛЬСТВО «ТЕХНОСФЕРА» ПРЕДСТАВЛЯЕТ КНИГУ:}

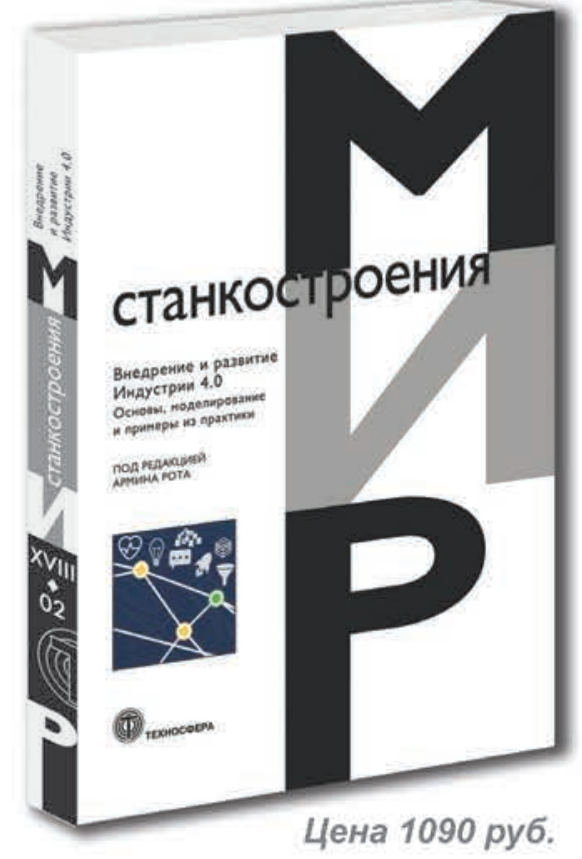

\section{ВНЕДРЕНИЕ И РАЗВИТИЕ ИНДУСТРИИ 4.0.}

Основы, моделирование

и примеры из практики

Под ред. Армина Рота

Пер. с нем. под общей ред. А.В. Кострова

М.: ТЕХНОСФЕРА, 2017. - 294 c.

ISBN 978-5-94836-482-7

\section{Издание осуществлено при финансовой} поддержке ПАО «Ростелеком»

В книге представлены концепция, основные парадигмы развития, структура технологии Индустрии 4.0. В отличие от широко распространенного технократического прикладного метода изучения, издание позволяет выделить и целостно описать уровни стратегического, тактического и оперативного управления. Ключевым элементом при этом является процессная модель, описывающая действия на стратегическом и оперативном уровнях, а примеры практического применения Индустрии 4.0 в различных отраслях промышленности наряду с мнениями известных экспертов в области науки и производства вызовут интерес не только у новичков отрасли, но и у научных сотрудников, инженерно-технических работников и руководителей высшего и среднего звена.

Благодаря обширному глоссарию издание станет ценным справочным пособием по использованию основных положений и лучших практик Индустрии 4.0.

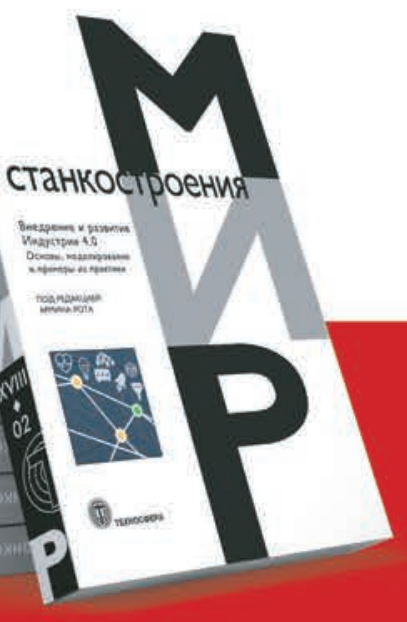

